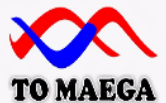

To Maega | Jurnal Pengabdian Masyarakat

Bulan-Tahun, Vol.3, No.2, hal.122-129

$\operatorname{ISSN}(P): 2622-6332 ; \operatorname{ISSN}(E): 2622-6340$

http://www.ojs.unanda.ac.id/index.php/tomaega

\title{
Peningkatan Kompetensi Pedagogik Guru melalui PKM Lesson Study
}

\author{
Rusdiana Junaid1a, Muhammad Rusli Baharuddin ${ }^{2 b^{*}}$ \\ ${ }^{1}$ Pendidikan Bahasa Inggris, FKIP, Universitas Cokroaminoto Palopo \\ ${ }_{2}^{2}$ Pendidikan Guru Sekolah Dasar, FKIP, Universitas Cokroaminoto Palopo \\ a,bEmail: rusdianajunaid@uncp.ac.id; mruslib@gmail.com; \\ *Correspondent Email: mruslib@gmail.com
}

Article History:

Received: 17-7-2020; Received in Revised: 20-7-2020; Accepted: 24-7-2020

DOI: http://dx.doi.org/10.35914/tomaega.v3.i2.413

\begin{abstract}
Abstrak
Mitra pada kegiatan ini adalah guru-guru SMP Negeri 8 Palopo sebagai upaya meningkatkan kompetensi pedagogik guru melalui PKM lesson study. Lebih dari 85\% siswa harus melakukan remedial ujian akhir semester agar memenuhi kriteria ketuntasan minimal. Program kemitraan ini bertujuan meningkatkan pengetahuan guru-guru SMP Negeri 8 Palopo tentang pemenuhan hak belajar siswa. Berdasarkan permasalahan yang dihadapi mitra maka solusi yang ditawarkan adalah pelatihan dan pendampingan lesson study. Hasil dari kegiatan ini adalah peningkatan kompetensi pedagogik yang ditandai dengan meningkatnya pengetahuan guru dalam bentuk membuat chapter design dan lesson design dengan berkolaborasi dengan teman sejawat, serta peningkatan pemenuhan hak belajar siswa ditandai dengan terciptanya suasana pembelajaran yang aktif, kreatif, efektif, inovatif, dan menyenangkan. Selain itu, PKM lesson study menghasilkan luaran berupa artikel ilmiah yang dipublikasi melalui jurnal nasional dan prosiding seminar international.
\end{abstract}

Kata Kunci: Lesson study, Kompetensi pedagogik, Hak belajar siswa

\begin{abstract}
Partners in this activity are the teachers of Palopo 8 Public Middle School in an effort to improve teacher pedagogical competence through PKM lesson study. More than $85 \%$ of students have to do a remedial final semester exam to meet the minimum completeness criteria. This partnership program aims to increase the knowledge of teacers of SMP Negeri 8 Palopo about fulfilling student learning rights. Based on the problems faced by partners, the solution offered is lesson study Training and Assistance. The rsults of this activity are an increase in pedagogical competence marked by increasing teacher knowledge in the form of creating chapter designs and lesson designs by collabrating with peers, as well as increasing the fulfillment of student learning rights marked by creating an atmosphere of active, creative, effective, innovative, and fun learning. In addition, PKM lesson study produces outcomes in the form of scientific articles published through national journals and international conference proceedings.
\end{abstract}

Key Word: Lesson study, Pedagogical competence, Student learning rights 

2020

\section{Pendahuluan}

Pendidikan adalah salah satu indikator kunci kemajuan suatu bangsa. Masyarakat Indonesia dengan laju pembangunannya masih menghadapi masalah pendidikan yang berat, khususnya bagaimana menyelenggarakan pendidikan yang tanggap dalam menghadapi tantangan revolusi industri 4.0. Dalam menyongsong era revolusi industri 4.0, bangsa Indonesia dituntut untuk berkompetisi dengan bangsa-bangsa lain di dunia dalam menguasai ilmu pengetahuan dan teknologi. Dengan demikian masalah pendidikan merupakan salah satu prioritas utama yang harus dipacu dalam menopang pembangunan untuk meningkatkan daya saing bangsa.

Dua dari delapan komponen penting dalam berlangsungnya pendidikan yaitu pendidik dan peserta didik. Untuk terus memperbaiki hasil, motivasi belajar, dan pemenuhan hak partisipasi, pendidik diharapkan mampu melakukan penelitian dan publikasi ilmiah. Kewajiban penelitian dan publikasi ilmiah mengacu pada Peraturan Menteri PAN No. 16 tahun 2009 pasal 11 yaitu salah satu kewajiban guru adalah melakukan publikasi ilmiah atas hasil penelitian atau gagasan inovatif dan mengembangkan diri melalui keikutsertaan dalam berbagai kegiatan peningkatan kompetensi dan keprofesian. Pemenuhan hak partisipasi anak sebagai komponen penting berlangsungnya pendidikan secara teknis diatur sesuai Permen PP-PA No 4 Thn 2011 tentang Juknis Kebijakan Partisipasi Anak dan Peraturan Presiden Nomor 75 Tahun 2015 tentang Rencana Aksi Nasional Hak Asasi Manusia Tahun 2015-2019.

Berdasarkan observasi awal tim pelaksna di SMP Negeri 8 Palopo terungkap fakta bahwa penyelenggaraan proses pembelajaran masih belum maksimal ditinjau dari aspek kompetensi pedagogik guru dan pemenuhan hak belajar siswa. Ada hal menjadi kendala dalam pelaksanaan proses pembelajaran yaitu dalam penyelenggaran pendidikan guru hanya berfokus aktivitas mengajar dan menilai siswa. Sedangkan berdasarkan undang-undang No.14 tahun 2005 tentang guru dan dosen pada Pasal 1 ayat 1 yaitu guru memiliki tugas utama mendidik, mengajar, membimbing, mengarahkan, melatih, menilai, dan mengevaluasi peserta didik pada pendidikan anak usia dini jalur pendidikan formal, pendidikan dasar, dan pendidikan menengah. Artinya kewajiban guru tentang hak belajar siswa belum tertunaikan secara maksimal.

Masalah kedua, kurang aktifnya beberapa anggota maupun pengurus dalam mengikuti kegiatan-kegiatan MGMP dan kurangnya koordinasi antara pengurus MGMP dengan Dinas Pendidikan dan pihak sekolah khususnya SMP Negeri 8 Palopo. Selain itu, Kegiatan MGMP masih bersifat insedentil dan belum secara spesifik mengarah pada sharing informasi sharing informasi tentang masalah dan alternatif solusi terhadap upaya pemenuhan hak belajar siswa.

Berdasarkan hasil audensi tim PKM dengan pihak sekolah, tertanggal 23 Juli 2018 terungkap fakta bahwa lebih dari 85\% siswa harus melakukan remedial 
ujian akhir semester agar memenuhi kriteria ketuntasan minimal (KKM). Berdasarkan permasalahan tersebut, tim pelaksana bersama guru-guru SMPN 8 Palopo menyepakati upaya peningkatan kompetensi pedagogik guru melalui PKM lesson study. Bentuk Kegiatan PKM lesson study sebagai solusi permasalahan mitra yaitu workshop lesson study, implementasi dan pendampingan penelitian lesson study, dan pembentukan learning community. Melalui solusi yang disepakati, diharapkan dapat meningkatkan kompetensi pedagogik guru dan memenuhi hak belajar siswa.

Meskipun merupakan sebuah ide sederhana, lesson study merupakan sebuah proses yang kompleks. Lesson study merupakan proses yang mengolaborasikan guru dalam grup kecil untuk merencanakan, mengajar, mengobservasi, meninjau kembali dan melaporkan hasilnya pada aplikasi dalam pengajaran individu.

Inovasi proses pembelajaran yang dirancang dan dikembangkan pada kegiatan lesson study ini bersifat aktif, praktis, menyenangkan, dan efektif. Dalam pelaksanaannya, kegiatan lesson study ini tidak bersifat instruksi atau menggurui, akan tetapi dilaksanakan secara kolaboratif antara dosen dan guru, guru dengan guru, dan guru pamong dengan guru praktikan. Upaya pencapaian hasil pada kegiatan lesson study secara maksimal perlu melibatkan banyak pihak, misalnya guru-guru bidang studi, kepala sekolah, MGMP dan dosen, praktisi pendidikan.

Implementasi lesson study secara kolektif kolegial dapat meningkatkan pengetahuan guru dalam menyusun rencana pembelajaran secara efektif melalui chapter design dan lesson design, peningkatan pengelolaan proses pembelajaran dengan menciptkan suasana pembelajaran yang aktif, kreatif, efektif, inovatif, dan menyenangkan, pengusahaan memanfaatkan media pembelajaran yang relevan dengan indikator capaian pembelajaran, dan ketepatan instrumen evaluasi pembelajaran dalam mengukur ketercapaian hasil belajar siswa.

\section{Metode}

Metode pelaksanaan dari PKM adalah workshop lesson study, implementasi lesson study penelitian dan pembentukan learning community. Metode pelaksanaan secara rinci dijelaskan sebagai berikut:

a. Workshop lesson study

Secara umum kegiatan ini di bagi menjadi dua yaitu pelatihan penelitian lesson study dan pembuatan perangkat pembelajaran. Pelatihan lesson study dengan melakukan studi literatur tentang pengantar penelitian lesson study dan kesadaran tentang pemenuhan hak belajar peserta didik, dan bahan demonstrasi (handout) tahapan penelitian lesson study (Plan, Do dan See) serta pembuatan angket kepuasan. Selain itu, Guru-guru juga dibekali dengan pengetahuan tentang pembuatan perangkat pembelajaran (RPP, LKS dan lembar Evaluasi) 
b. Implementasi penelitian lesson study.

Implementasi penelitian lesson study dilakukan beberapa siklus yang didokumentasi melalui rekaman video dan setiap sikulus akan melalui tahap Plan, Do, dan See.

Tahap Plan: Tim pengusul dan guru akan mengidentifikasi permasalahan dalam proses pembelajaran, merencanakan langkah-langkah pembelajaran dan memaparkan perangkat pembelajaran yang akan disajikan. Sedangkan pada tahap plan berikutnya akan menindak lanjuti hasil evaluasi/refleksi.

Tahap Do: Guru Model melaksanakan proses pembelajaran sedangkan tim pengusul dan guru-guru yang lain bertindak sebagai observer. Observasi dilakukan dengan memperhatikan secara saksama setiap aktivitas siswa dan memastikan pemenuhan hak belajar siswa tersebut.

Tahap See: Guru Model dan observer akan menyampaikan hasil pengamatan yang terjadi selama pelaksanaan Do. Temuan dari hasil observasi tersebut akan di jadikan dasar untuk memperbaiki plan Selanjutnya.

\section{c. Pembentukan learning community}

Peserta pelatihan dan pendampingan pebelitian lesson study akan tergabung dalam learning comunity for lesson study Kota Palopo, untuk menambahkan keanggotaan learning community maka calon anggota harus pernah terlibat dalam penelitian lesson study yaitu minimal sebagai observer.

\section{d. Evaluasi pelaksanaan dan rencana keberlanjutan}

Setelah melakukan semua kegiatan PKM, mitra akan diminta mengisi angket kepuasan untuk mengukur apakah PKM ini efektif atau tidak dan memberikan saran untuk kegiatan PKM selanjutnya. Langkah terakhir dalam tahap ini adalah pembuatan laporan serta mempersiapkan luaran yang dijanjikan.

Rencana keberlanjutan program melibatkan mitra untuk terus mengembangkan dan berinovasi dalam melakukan penelitian. Selain itu, hal utama dalam keberlanjutan program ini adalah adanya publikasi ilmiah yang dilakukan oleh guru-guru di SMP Negeri 8 Palopo. Universitas Cokroaminoto Palopo akan membantu dalam hal konsultasi pembuatan artikel ilmiah yang siap dipublikasikan dalam jurnal dan juga seminar nasional, serta menyediakan jurnal untuk media publikasi ilmiah guru-guru mitra. Sebagai tambahan penunjang keberlanjutan program PKM maka guru akan dibekali buku saku tentang metodologi penelitian dan penulisan artikel ilmiah. 
[ 126 ] Rusdiana Junaid, dkk / To Maega : Jurnal Pengabdian Masyarakat, Vol.3; No.2; Agustus, 2020

\section{Hasil dan Pembahasan}

a. Persiapan kegiatan PKM lesson study

Persiapan kegiatan PKM lesson study dilakukan pada tanggal 1 s/d 19 Juli 2019. Kegiatan yang dilakukan dalam persiapan yaitu melakukan pengurusan ijin pelaksanaan, penentuan jadwal sekolah dan narasumber workshop lesson study, melakukan study literatur dan masukan pakar lesson study, pembuatan handout dan materi workshop dan penyusunan angket kepuasaan.

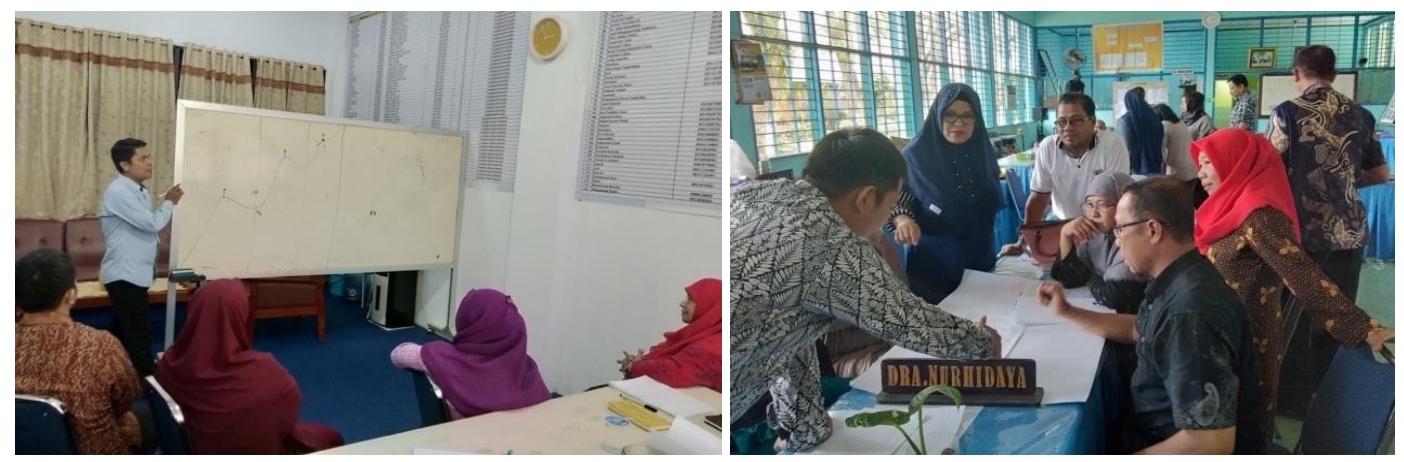

Gambar 1. Persiapan pelaksanaan PKM lesson study

b. Workshop lesson study

Materi pada kegiatan workshop lesson study ini adalah, The history of lesson study, Strategi merancang pembelajaran yang berpusat pada mahasiswa, Lesson study berbasis sekolah (LSBS), Praktik chapter design, Praktik lesson design, Praktik open lesson, dan Praktik refleksi pembelajaran.

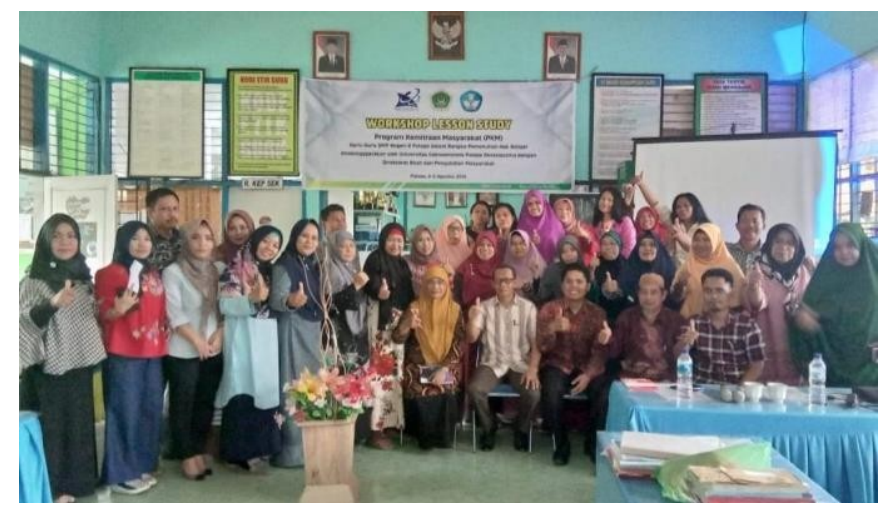

Gambar 2. Workshop lesson study

Hasil dari kegiatan ini adalah memberikan pengenalan dan pemahaman kepada guru bagaimana memenuhi hak belajar peserta didik. Selain itu, dapat meningkatkan kualitas proses pembelajaran dengan menggeser paradigma lama menjadi student learning center yang tercipta melalui proses pembelajaran kolaboratif dan kolegial. Antusiasme para guru dalam mengikuti kegiatan workshop menjadi alasan kuat bagi kepala sekolah untuk tetap menyelenggarakan kegiatan lesson study di SMP Negeri 8 Palopo setiap tahunnya. 
[ 127 ] Rusdiana Junaid, dkk / To Maega : Jurnal Pengabdian Masyarakat, Vol.3; No.2; Agustus, 2020

\section{c. Implementasi Lesson Study}

Tahapan implemetasi lesson study adalah Plan, Do dan See yang dipaparkan rinci sebagai berikut:

Tahap Plan: Perencanaan dilakukan secara kolaboratif oleh beberapa orang guru yang termasuk dalam suatu kelompok lesson study. Perencanaan diawali dari analisis permasalahan yang dihadapi dalam pembelajaran. Permasalahan dapat berupa materi bidang studi, bagaimana menjelaskan suatu konsep. Permasalahan dapat juga berupa pedagogik tentang metode pembelajaran yang tepat agar pembelajaran lebih efektif dan efisien atau permasalahan fasilitas. Selanjutnya guru secara bersama-sama mencari solusi terhadap permasalahan yang dihadapi yang dituangkan dalam RPP atau lesson plan.
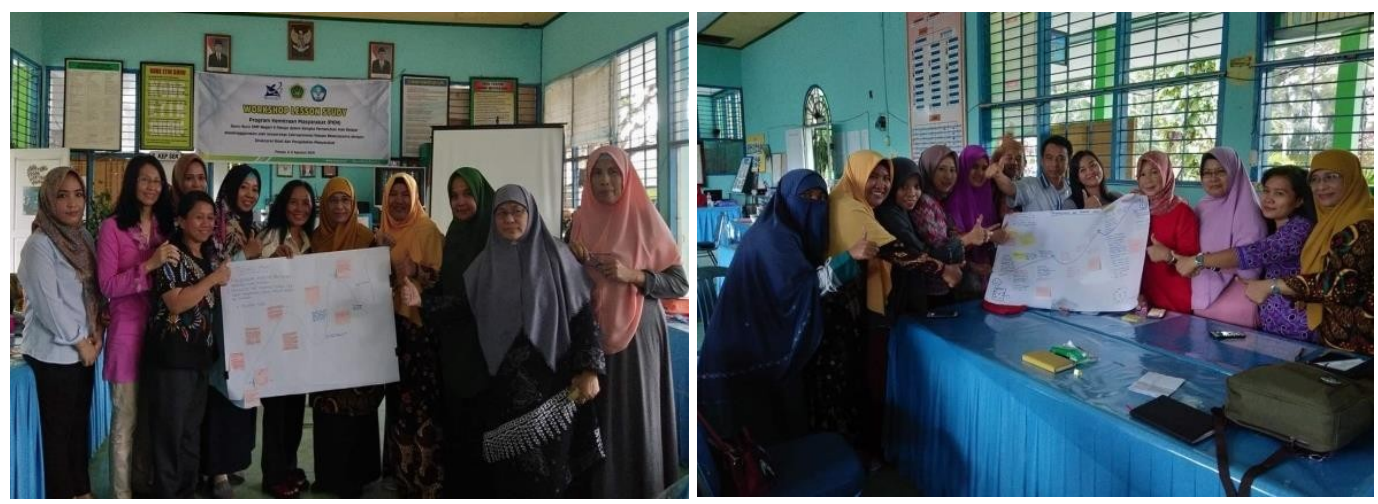

Gambar 2. Pelaksanaan Plan

Tahap Do: Pelaksanaan pembelajaran, dimaksudkan untuk menerapkan rancangan pembelajaran yang telah direncanakan. Salah satu anggota kelompok berperan sebagai guru model, sedangkan anggota kelompok lainnya mengamati (observer). Fokus pengamatan diarahkan pada kegiatan belajar peserta didik dengan berpedoman pada prosedur dan instrumen yang telah disepakati pada tahap perencanaan, bukan pada penampilan guru yang sedang bertugas mengajar. Selama pembelajaran berlangsung, para pengamat tidak diperkenankan mengganggu proses pembelajaran walaupun mereka boleh merekam dengan kamera video atau kamera digital.
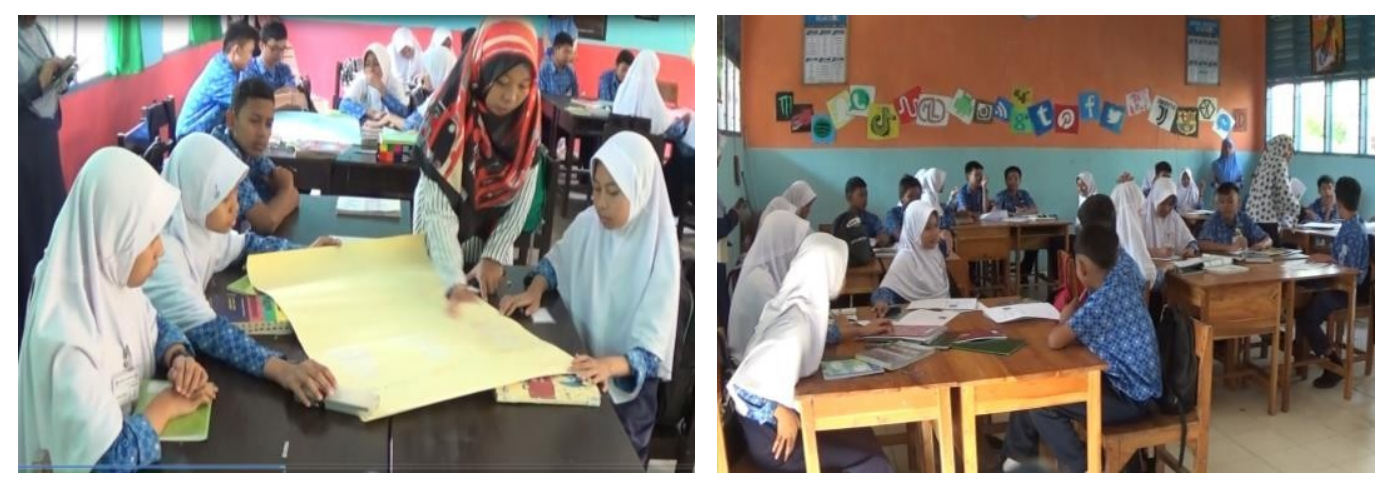

Gambar 3. Pelaksanaan Do 
Tahap See: Setelah selesai pembelajaran langsung dilakukan diskusi antara guru dan observer yang dipandu oleh kepala sekolah untuk membahas pembelajaran. Guru model mengawali diskusi dengan menyampaikan kesan-kesan dalam melaksanakan pembelajaran.

Selanjutnya pengamat menyampaikan hasil pengatamatan dalam proses pembelajaran terkait aktivitas siswa, kritik dan saran disampaikan secara bijak demi perbaikan pembelajaran. Sebaliknya, guru model menerima masukan dari observer untuk perbaikan pembelajaran berikutnya.
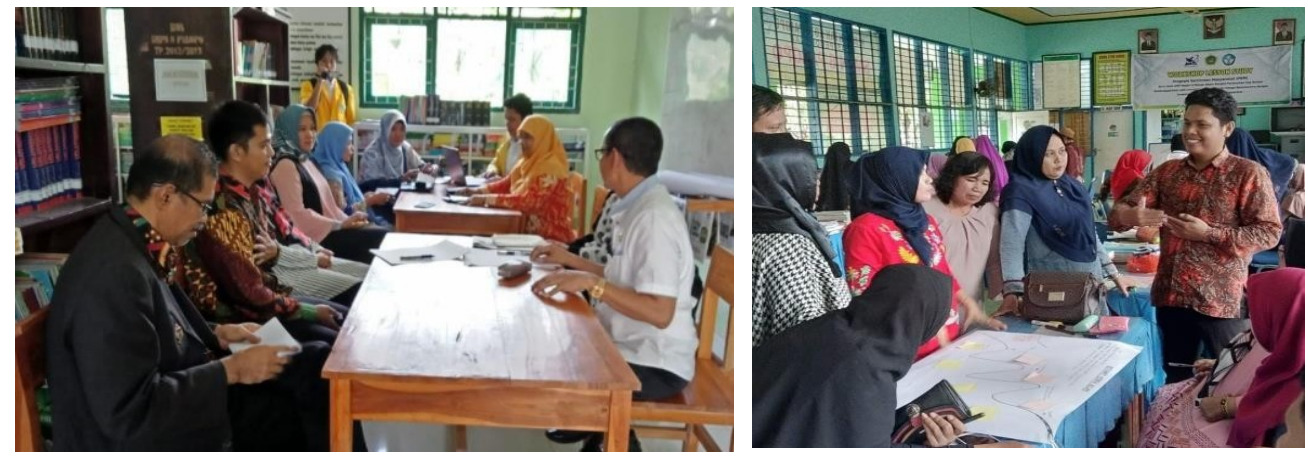

Gambar 4. Pelaksanaan Refleksi

\section{Kesimpulan}

Program kemitraan masyarakat yang dilakukan pada guru-guru SMP Negeri 8 Palopo yaitu workshop lesson study, implementasi lesson study penelitian dan pembentukan learning community. Sebagai manfaat yang diperoleh guru dalam PKM ini adalah peningkatan kompetensi pedagogik guru yang ditandai dengan peningkatan pengetahuan dalam memanfaatkan media pembelajaran inovatif, merencanakan pembelajaran melalui lesson design, mampu menyusun bahan ajar, pengelolaan proses pembelajaran secara interaktif, dan mampu melakukan evaluasi/refleksi proses pembelajaran.

Kegiatan program kemitraan masyarakat yang dilakukan pada guru-guru SMP Negeri 8 Palopo sebagai langkah awal dalam melahirkan guru professional yang sadar akan pentingnya hak belajar siswa. Diharapkan kegiatan ini dapat berlanjut dengan melibatkan rekan guru lain dan MGMP.

\section{Ucapan Terimakasih}

Tim Penulis mengucapkan terima kasih kepada Direktorat Riset dan Pengabdian Masyarakat, Direktorat Jenderal Penguatan Riset dan Pengembangan. Kementrian Riset, Tekonologi, dan Pendidikan Tinggi atas bantuan pendanaan untuk menunjang terlaksananya program kemitraan masyarakat bagi guru-guru SMP Negeri 8 Palopo dalam menjamin hak belajar siswa. 
[ 129 ] Rusdiana Junaid, dkk / To Maega : Jurnal Pengabdian Masyarakat, Vol.3; No.2; Agustus, 2020

\section{Daftar Pustaka}

Doig, B., \& Groves, S. (2011). Japanese lesson study: Teacher professional development through communities of inquiry. Mathematics Teacher Education and Development, 13(1), 77-93.

Fernandez, C., \& Yoshida, M. (2012). Lesson study: A Japanese approach to improving mathematics teaching and learning. London: Routledge Publishers,

Hikmawati, H., \& Jufri, A. W. (2020). PKM Kelompok Guru IPA dalam Pembuatan Media Pembelajaran Berbasis Lesson Study di SMP Negeri 16 Mataram. Jurnal Pepadu, 1(2), 207-212.

Juano, A., Ntelok, Z. R., \& Jediut, M. (2019). Lesson Study sebagai Inovasi untuk Peningkatan Kualitas Pembelajaran. Randang Tana: Jurnal Pengabdian Masyarakat, 2(2), 126-136.

Jumarniati, J., Kartika, D. M. R., \& Baharuddin, M. R. (2018). Penerapan Model Pembelajaran Kooperatif pada Mata Kuliah Program Linear Melalui Lesson Study. MaPan: Jurnal Matematika dan Pembelajaran, 6 (2), 187-198.

Jumarniati, J., Saruman, S. H., \& Baharuddin, M. R. (2019). Perempuan Penjual Pecel Lamasi, Kecamatan Lamasi, Kab. Luwu Sulawesi Selatan Sebagai Pilar Ekonomi Keluarga. Caradde: Jurnal Pengabdian Kepada Masyarakat, $1(2), 105-110$.

Lieberman, J. (2009). Reinventing teacher professional norms and identities: The role of lesson study and learning communities. Professional Development in Education, 35(1), 83-99

Riyati, S. (2007). Sistem Pembinaan Profesional Guru Pendidikan IPA Melalui Lesson Study. Bandung: Jurusan Pendidikan Biologi FPMIPA Universitas Pendidikan Indonesia.

Subadi, T. (2010). Lesson Study Berbasis PTK (Penelitian Tindakan Kelas). Surakarta: Badan Penerbit FKIP UMS 